\title{
Metastasis to the male breast from carcinoma of the urinary bladder - a rare case report
}

\author{
Swechha Maskey ${ }^{1}$, Kapendra Shekhar Amatya ${ }^{2}$, Banita Gurung ${ }^{1}$, Suniti Shrestha ${ }^{1}$, \\ Moushami Singh ${ }^{1}$, Shivani Sharma ${ }^{3}$, Hari Prasad Dhakal ${ }^{1}$ \\ ${ }^{I}$ Department of Pathology and Laboratory Medicine, Nepal Cancer Hospital and Research Center(NCHRC), Harisiddhi, Lalitpur, Nepal \\ ${ }^{2}$ Department of Surgical Oncology, Nepal Cancer Hospital and Research Center(NCHRC), Harisiddhi, Lalitpur, Nepal \\ ${ }^{3}$ CORE Diagnostics, Gurgaon, India
}

\author{
Keywords: \\ Male breast; \\ Metastasis; \\ Urothelial carcinoma;
}

\begin{abstract}
Metastasis to the male breast is rarer than that of the female breast. Primary tumors of the urinary bladder to metastasize to the breast is more uncommon than other sites like lungs, ovary, or stomach. We report a case of a 59-year-old male patient with proven high-grade urothelial carcinoma of the bladder with lungs and anterior abdominal metastasis, presented with ulceroproliferative mass in the left breast nipple-areolar complex. Wide local excision was done and was sent for histopathological examination which showed neoplastic cells, morphologically resembling urothelial carcinoma. Immunohistochemical staining showed tumor cells positive for CK5/6, p63, GATA3, and Uroplankin, which confirmed the diagnosis and demonstrated the urothelial origin. There are no such cases reported to date in Nepal and very few cases are reported worldwide. Diagnostic accuracy depends on histologic analysis. Distinguishing between metastasis to the breast and primary breast tumor is important for therapy and prognosis.
\end{abstract}

\section{Correspondence:}

Dr. Swechha Maskey, MD

Department of Pathology and Laboratory Medicine

Nepal Cancer Hospital and Research Center(NCHRC), Harisiddhi,

Lalitpur, Nepal

Orcid id: 0000-0002-4641-4183

Email:dr.swechha@gmail.com

Reveived : September $20^{\text {th }} 2020$; Accepted : December $6^{\text {th }} 2020$

Citation: Maskey S, Amatya KS, Gurung B, Shrestha S, Singh M, Sharma S, Dhakal HP. Metastasis to the male breast from carcinoma of the urinary bladder - a rare case report. Journal of Pathology of Nepal 2021;12(2): 1870-2. DOI: 10.3126/jpn.v11i1.31629

Copyright: This is an open-access article distributed under the terms of the Creative Commons Attribution 4.0 International License, which permits unrestricted use, distribution, and reproduction in any medium, provided the original author and source are credited.

\section{INTRODUCTION}

Metastasis to the breast from extramammary malignancies accounts for only $0.43 \%$ of all malignant breast tumors. ${ }^{1}$ The common sources of metastasis to the breast are lymphomas/leukemias and melanomas. ${ }^{2}$ Breast metastasis from urothelial carcinoma is extremely rare, with few cases reported to date. ${ }^{1}$ We herein report a case of a 59 -years-old male patient with breast metastasis from primary urothelial carcinoma in the urinary bladder due to its rarity.

\section{CASE REPORT}

A 59-years-old male patient with proven high-grade urothelial carcinoma of the urinary bladder with lungs 


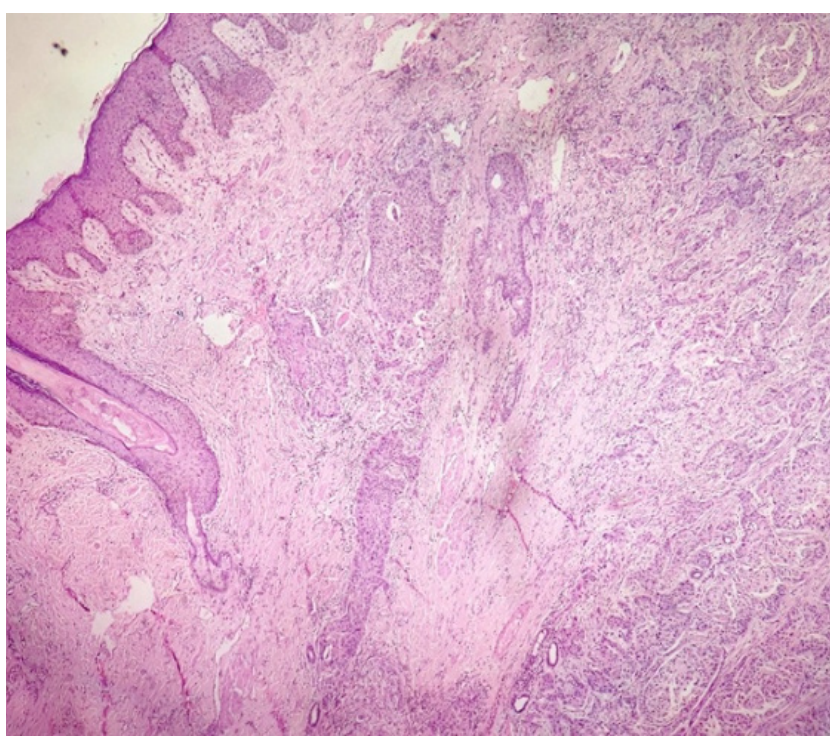

Figure 1: Histologic picture shows tumor cells in sheets and nests with surrounding desmoplastic stroma and overlying epidermis of the nipple-areolar complex. (HE stain, X40)

and anterior abdominal wall metastasis, treated with radical cystoprostatectomy and received palliative chemotherapy, presented with an ulceroproliferative mass in the left breast nipple-areolar complex region measuring $6.5 \times 5.5 \times 1.4 \mathrm{~cm}$. Wide local excision was done and was sent to our department for histopathological examination. Histomorphology of the lesion showed neoplastic cells infiltrating between the normal ducts. The tumor cells are arranged in sheets and nests having moderate nuclear pleomorphism, hyperchromatic nuclei, prominent nucleoli, and a moderate amount of eosinophilic cytoplasm, morphologically resembling urothelial carcinoma (fig. 1). In immunohistochemical analysis, tumor cells were positive for CK5/6, p63, GATA3(fig.2), and Uroplankin (fig.3) and negative for GCDFP15, which confirmed the diagnosis of the urothelial origin.

\section{DISCUSSION}

Male breast carcinoma represents only $1 \%$ of all male malignancies. A retrospective review of 51 patients with tumor metastasis to the breast included only one patient with a primary malignant bladder tumor. Suspicion of metastasis was raised when a sharply defined nodule occurred in the subcutaneous fat rather than in glandular tissue and in an unusual or eccentric location of the breast. ${ }^{3}$

Metastatic spread to the male breast is extremely rare but has been reported from prostatic carcinoma treated with hormone therapy. ${ }^{3}$ Metastatic cancer in the male and female breast has been reported in cutaneous melanoma, renal adenocarcinoma, lymphoma, and leukemia. Only two cases of breast metastasis from urinary bladder carcinoma have been previously reported, both in a female patient. ${ }^{4}$ To the best of our knowledge, the present study is the third described case of male breast metastasis from

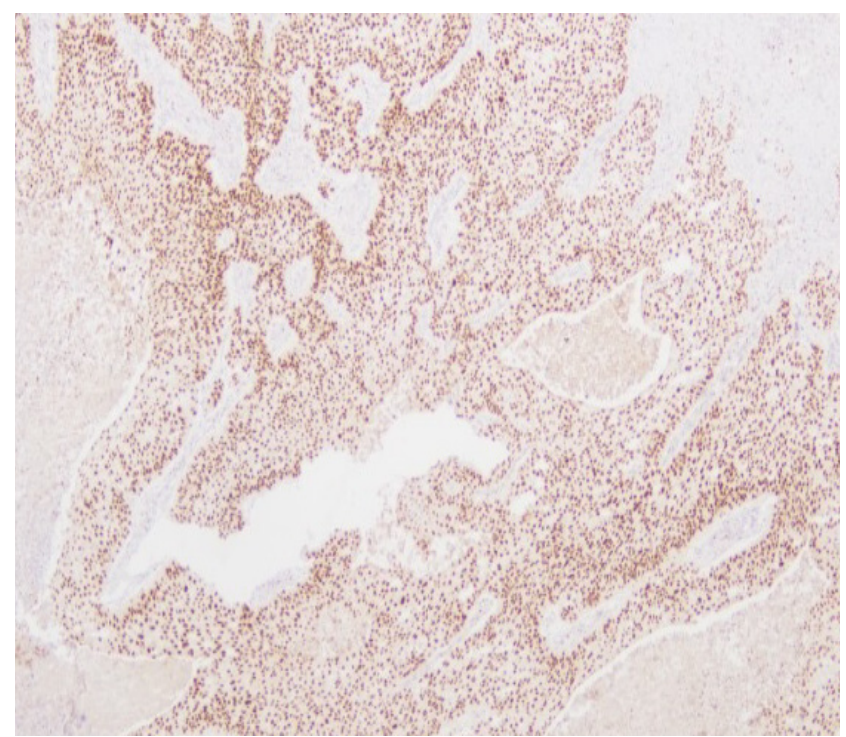

Figure 2: Gata 3: Positive nuclear staining in tumor cells. (X40)

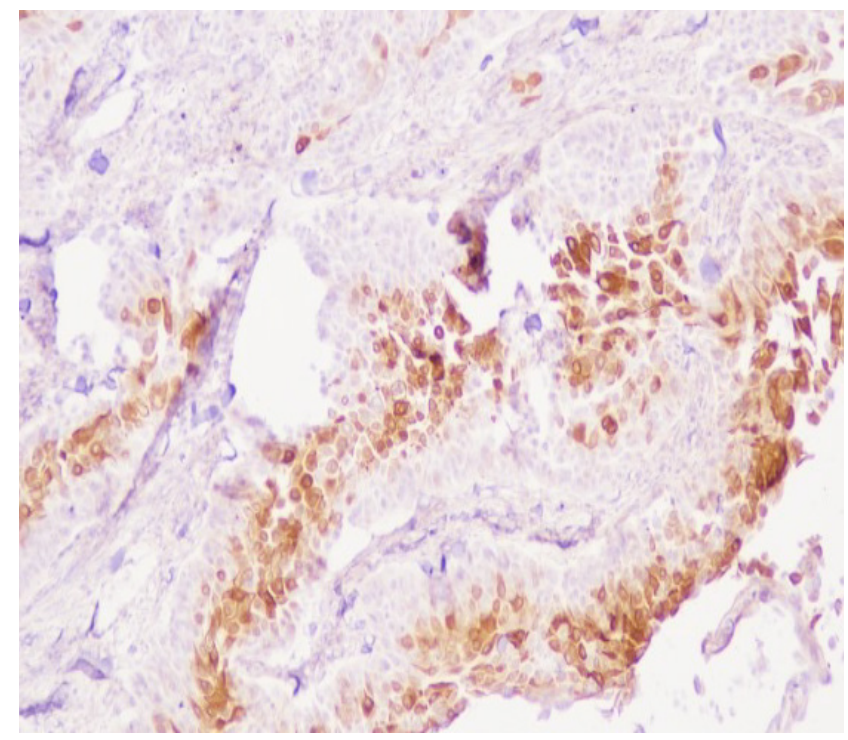

Figure 3: Uroplakin: Positive cytoplasmic and membranous staining in tumor cells. (X100)

urinary bladder carcinoma. The first case of carcinoma of the bladder metastatic to the male breast was reported by Truesdale et al. in 1979, followed by Cappabianca et al. in $2000 ., 5$

The first detailed description of a case of transitional cell carcinoma of the bladder, metastasis to the breast as the first evidence of widely metastatic bladder carcinoma was reported by Berkman et al. in 1982. ${ }^{6}$ The case presented by Chen et al. represents the first description of a primary signet ring cell carcinoma of the urinary bladder with breast metastasis. ${ }^{1}$

In a study of 107 patients with histologically proven transitional cell carcinoma of the urinary bladder, the most common sites for metastasis were lymph nodes, liver, lung, bone, and adrenal gland. None was found to have 
breast metastasis although all patients died of metastatic transitional cell carcinoma of the urinary bladder. The majority of these patients presented initially with highgrade tumors suggests that high-grade lesions warrant early aggressive therapy. ${ }^{7}$

A retrospective study done by Buisman et al., comprised 47 patients with breast metastasis, out of which 40 were females and 7 males. The most common primary neoplasm was lymphoma, followed by melanoma. Other primary tumor sites included the ovary, lung, colon, kidney, stomach, and chorion. None of the breast metastasis was from urinary bladder carcinoma. ${ }^{8}$

A case study reported a 57-year woman with a right breast lesion along with a nodule on the patient's back demonstrated metastatic transitional cell carcinoma located in the subcutaneous fat of the breast and back. The patient died 8 months later despite aggressive chemotherapy. ${ }^{9}$ Metastatic transitional cell carcinoma is often associated with high-grade lesions and invasion of the detrusor muscle. Fewer than $50 \%$ of patients with muscle-invasive bladder cancer will survive 5 years despite aggressive therapy. ${ }^{9}$

\section{CONCLUSION}

Metastatic spread to the male breast is extremely rare. Owing to its rarity, an appropriate diagnosis is important for therapy and prognosis. Definite diagnosis requires histopathological evaluation supported by immunohistochemistry. Earlier recognition of metastatic tumor in the breast may result in appropriate therapy and will preclude unnecessary mastectomy. ${ }^{7}$

\section{Conflict of interest: None}

\section{REFERENCES}

1. Chen Y, Wei H, Li $\mathrm{J}$ et al. Breast metastasis from signet ring cell carcinoma of the urinary bladder: a case report. Molecular and Clinical Oncology 2016;13:111-2. Crossref

2. Vaidya T, Ramani S, Rastogi A. A case series of metastases to the breast from extramammary malignancies. Indian J Radiol Imaging 2018;28:470-5. Crossref

3. Hadju SI, Urban JA. Cancers metastatic to the breast. Cancer 1972 ;29:1691-6. Crossref

4. Cappabianca S, Grassi R, D'Alessandro P et al. Metastasis to the male breast from carcinoma of the urinary bladder. The British Journal of Radiology 2000;73:1326-8. Crossref

5. Truesdale BH, Johnson RD, Evins SC. Carcinoma of bladder metastatic to breast. Urology 1979;13:430-1. $\underline{\text { Crossref }}$
6. Berkman AW, Markman M, Murphy JB et al. Transitional cell carcinoma of the bladder metastatic to the breast. Med Pediatr Oncol 1982;10: 141-4. Crossref

7. Babaian RJ, Johnson DE, Llamas L et al. Metastases from transitional cell carcinoma of urinary bladder. Urology 1980;16:142-4. Crossref

8. Buisman FE, Geldar LV, Menke-Pluijmers MBE et al. Non-primary breast malignancies: a single institution's experience of a diagnostic challenge with important therapeutic consequences-a retrospective study. World Journal of Surgical Oncology 2016;14:166. Crossref

9. Belton AL, Stull MA, Grant T, Shepard MH. Mammographic and sonographic findings in metastatic transitional cell carcinoma of the breast. American Journal of Roentgenology 1997;168:511-2. Crossref 